\title{
LYING, SPEECH AND IMPERSONAL HARM
}

(Accepted 22 November 2018)

\begin{abstract}
Should the law punish the mere utterance of lies even if the listener has not been deceived? Seana Shiffrin has recently answered this question in the affirmative. She argues that pure lying as such harms the moral fabric of sincerity and distorts the testimonial warrants which underpin communication. The article begins with a discussion of Shiffrin's account of lying as a moral wrong and the idea of impersonal harm to moral goods. Then I raise two objections to her theory. First, it does not explain persuasively why the fabric of sincerity is so vulnerable to pure lying. Second, it underestimates the need for a causal link between the alleged harm and the speech the government suppresses. I explore the function of the causal inquiry in constitutional law and suggest that if Shiffrin's theory were to become the standard for adjudication in freedom of expression cases, protection for speech would deteriorate.
\end{abstract}

\section{LYING AS A WRONG}

Lying, Seana Shiffrin explains in Speech Matters, ${ }^{1}$ is a moral and legal wrong. ${ }^{2}$ In her view, a lie is an assertion that the speaker knows she does not believe, but nevertheless deliberately asserts, in a context that, objectively interpreted, represents that assertion as to be taken by the listener as true and as believed by the speaker.' 3 Such assertions interfere with the possibility of expressing our genuine mental contents and accessing the mental contents of others, which, in turn, is necessary for our development as moral agents. Therefore, there is

\footnotetext{
${ }^{1}$ Seana Valentine Shiffrin, Speech Matters: On Lying, Morality and the Law (Princeton: Princeton University Press, 2014) (hereafter: Shiffrin, Speech).

${ }^{2}$ Shiffrin, Speech 162.

${ }^{3}$ Shiffrin, Speech 116. See also the discussion in pages 12-16.
}

\footnotetext{
${ }^{\star}$ City, University of London. An earlier version of the article was presented at a conference at University College London. I am grateful to members of the audience, and to an anonymous reviewer for Law and Philosophy, for comments and suggestions.
} 
a 'moral presumption of truthfulness in communication' which encompasses 'a requirement of sincerity, namely that one believe what one says when one solemnly affirms it, as well as a requirement to exert some effort to be accurate about what one says. ${ }^{, 4}$

This is a view of sincerity which requires that the assertion be a genuine representation of the speaker's mental content; where there is a discrepancy between the two, the communication is a lie. The same concern is reflected in R.M. Hare's definition of insincerity as 'not saying what one really thinks. ${ }^{5}$ Thus, the essence of sincerity is taken to be truthfulness, and speech must correspond to the speaker's thoughts to qualify as truthful. ${ }^{6}$ For Shiffrin, truthful speech in that sense is the means to address 'our mutual epistemic limitations and the complexity of the environment in which we find ourselves'. ${ }^{7}$ By communicating our thoughts and accessing the thoughts of others we engage in a learning process about ourselves and them, about our political community and the wider world, and about the requirements of morality. We learn what it means to be human, and to live as one, in a complex world. Therefore, we value truthful speech and, as we will see later, we expect the law to offer it a very robust protection because it is the epistemic medium for accessing others' genuine mental content, which is a prerequisite for thinking about the human condition.

Further, Shiffrin argues that the speaker's intent to deceive or the likelihood of his utterance deceiving the listener are not prerequisites for lying: 'a lie does not depend upon its recipient being deceived or upon its issuer intending to deceive the recipient. ${ }^{, 8}$ It is enough that the speaker is falsifying the contents of her mind when communicating them to another person. In speech contexts, such falsification is a lie even if the speaker does not intend to affect the beliefs of her listeners or knows that her utterance will not be believed by them.

This definition of a lie is important for Shiffrin's explanation of the wrongness of lying. She argues that it inhere[s] in the production

\footnotetext{
${ }^{4}$ Shiffrin, Speech 11.

${ }^{5}$ R.M. Hare, Freedom and Reason (Oxford: Clarendon Press, 1963) 83.

${ }^{6}$ A different account of sincerity as an exclusion of contrary thoughts in relation to the subject about which the speaker is making an utterance is developed in Stuart Hampshire, "Sincerity and SingleMindedness" in Freedom of Mind and Other Essays (Oxford: Oxford University Press, 1972) 232. This is not an issue for Shiffrin who focuses on the correspondence between thought and speech.

${ }^{7}$ Shiffrin, Speech 9.

${ }^{8}$ Shiffrin, Speech 13. On the differences between lies and deceptions see the discussion in pages 19-21.
} 
and expression of a lie'. ${ }^{9}$ Lying is morally wrong qua lying-irrespective of the liar's intent or the effect of his falsehoods on the audience-because it spoils the possibility of relying on others' communicative utterances as a means of accessing their minds. Since testimony is the only way of knowing what others think, it needs to be preserved as a mechanism for the expression of truth. Lying turns it into a mechanism 'for conveying both the false and the true. ${ }^{, 10}$ But, then, we cannot be certain that what we are being told is a genuine representation of the speaker's thoughts; the presumption of truthfulness no longer works. Using speech to convey falsehoods 'eliminate[s] a fail-proof, trustworthy mode of access to one another. Because there are no external methods of verification - no means by which others may peer into one's mind-to lie is to sully the one road of authoritative access to oneself and thereby cut oneself off from community with others. Doing so frustrates achievement of the compulsory moral ends associated with mutual understanding and cooperation. ${ }^{11}$

\section{IMPERSONAL HARM}

The fact that lying is morally wrong is not a sufficient condition for making it a legal wrong too. We wouldn't think that the government is justified in punishing every moral wrong, nor would we find the prospect of living under such a regime attractive. Something more is required before our moral failures can legitimately become the business of the state. A usual candidate is harm: where a moral wrong causes harm to another or, in some cases, to oneself, the government may have reason to act. Shiffrin follows this path. She argues that lying can be harmful in different ways and this justifies legal regulation. Sometimes there will be competing reasons against curtailing falsehood. The example she discusses in detail is that of autobiographical lies which do not deceive the listener. ${ }^{12}$ Her view is that we should refrain from punishing the liar because such an attitude 'conveys a compassionate acknowledgement of our shared, flawed humanity and the message that we are willing to continue on

\footnotetext{
${ }^{9}$ Shiffrin, Speech 19.

${ }^{10}$ Shiffrin, Speech 23.

${ }^{11}$ Shiffrin, Speech 23.

${ }^{12}$ Shiffrin, Speech chapter 5.
} 
together despite our predictable failures. ${ }^{13}$ Yet, the underlying rationale is not speech but 'equality, fraternity and toleration'. ${ }^{14}$ Put differently, speech does not provide a reason which can override the governmental interest in suppressing lies.

This conclusion is linked to Shiffrin's account of the harm caused by lying. Clearly speech in general can cause harm ${ }^{15}$ and false speech in particular is often the subject of state regulation through civil or criminal law. A classic case is the protection of an individual's reputation from harm caused by false allegations. Other examples include perjury, false statements to the police and fraudulent misrepresentation. What those cases have in common is that lying causes a specific harm, to a person or a legitimate state objective such as solving a crime, which is a fact that is reason for governmental regulation.

For Shiffrin, such specific 'legally cognizable harm'16 is not a necessary condition for the exercise of state coercion. Even if the lie is not directed to a particular individual and the liar is not trying to gain material advantage for himself the government can legitimately hold him legally responsible because his lying harms 'the culture of trust'. ${ }^{17}$ She argues:

'[D]eliberately false speech does damage to our collective testimonial framework by giving us reasons to doubt that a person's word is reliable as such and that somber testimonial speech provides us with warrants to take what is offered as representing what is believed. That is, deliberately insincere speech does collective harm by ambiguating signals that function well only when fairly clear, signals whose preservation and use are crucial for sustaining a functioning moral and political culture. ${ }^{18}$

Thus, lying qua lying is not only a moral wrong but becomes a legal wrong too because it harms a cultural presumption that the speaker's words are a true reflection of his mental content. The government does not need to point to a specific victim; the victim is the moral fabric of society. In Joel Feinberg's classification of laws that restrict individual liberty, Shiffrin's law that punishes pure lying

\footnotetext{
${ }^{13}$ Shiffrin, Speech 164.

${ }^{14}$ Shiffrin, Speech 118.

${ }^{15}$ See e.g. Frederick Schauer, 'Harm(s) and the First Amendment' (2011) The Supreme Court Review 81.

${ }^{16}$ Shiffrin, Speech 157.

${ }^{17}$ Shiffrin, Speech 137.

${ }^{18}$ Shiffrin, Speech 136.
} 
is a form of critical moralism, as it aims to enforce through state coercion true moral norms of communication. ${ }^{19}$

The collective harm Shiffrin refers to as a justification for censoring the liar is different from the type of collective harm that advocates of hate-speech prohibition like Jeremy Waldron have relied on. ${ }^{20}$ The argument in the latter case is that hate speech, even when not directed against a particular person, targets groups whose members share a specific characteristic like race, religion or sexual orientation and aims to "besmirch the basics of their reputation ${ }^{21}$ and assault their dignity in the sense of equal 'social standing. ${ }^{22}$ The target may be a group, and therefore a collective element is present, but the harm is personal. By contrast, in Shiffrin's account it is the 'basis $^{23}$ or 'collective fabric' ${ }^{24}$ or 'moral culture ${ }^{25}$ of trust that is allegedly damaged. This is a form of impersonal harm to an abstract moral good.

To sum up: lying, in the sense of deliberately misrepresenting one's mental content to another, is a moral wrong regardless of the intention of the speaker or the effect his lie has on other people's minds. It is also a legal wrong and the state can legitimately punish liars because they harm the moral fabric of trust. This harm, although non-specific and impersonal, is sufficient reason for the exercise of state coercion.

\section{LYING AND FREEDOM OF EXPRESSION}

What happens when Shiffrin's theory meets constitutional doctrine on freedom of speech? Her discussion of United States $v$ Alvarez ${ }^{26}$ is illuminating. The defendant, who was active in local government politics, had falsely claimed during a district board meeting that he was the recipient of the Congressional Medal of Honor and was subsequently convicted of violating the Stolen Valor Act of 2005, a federal statute that made it a criminal offence to falsely represent

\footnotetext{
${ }^{19}$ Joel Feinberg, Harmless Wrongdoing (Oxford: Oxford University Press, 1990) 124.

${ }^{20}$ Jeremy Waldron, The Harm in Hate Speech (Cambridge, Mass.: Harvard University Press, 2012).

${ }^{21}$ Waldron, Hate Speech 5.

${ }^{22}$ Waldron, Hate Speech 5.

${ }^{23}$ Shiffrin, Speech 131.

${ }^{24}$ Shiffrin, Speech 157.

${ }^{25}$ Shiffrin, Speech 163.

${ }^{26}$ United States v Alvarez, 132 S. Ct. 2537 (2012).
} 
oneself to have received a decoration or award for distinguished military service. The speaker's aim in lying and the effect his lie had on the audience were irrelevant for the issue of his criminal liability as the Act did not require a showing that he intended to deceive or that his listeners were actually deceived. It punished the telling of a lie as such; the fact that the speaker had knowingly misrepresented his mental content was enough to trigger his conviction.

The Supreme Court held that the Act violated the First Amendment. It noted that while there were several instances where the government could legitimately regulate false speech there was no rule that such speech 'should be in a general category that is presumptively unprotected'. ${ }^{27}$ The Act was proscribing speech on the basis of its content in a 'sweeping, quite unprecedented'28 way: it covered all statements regardless of the place (public or private) or the context (family, social or political) in which they were made and ignored their purpose. The moment the lie was uttered the government could punish the liar without any additional requirements whatsoever. In other words, the Act lacked 'limiting features, ${ }^{29}$ which could have functioned as safeguards against the risk of excessive censorship. This concern about the Act's overbroad reach was exacerbated by the fact that it did not require the government to show that there was a causal link between the conduct it criminalised (lying about a medal or award) and the alleged harm it sought to prevent (compromising the integrity and purpose of the award), nor had the government been able to show that in this particular case the defendant's false claim had had such an effect.

Shiffrin thinks that we have good moral reasons to let the defendant go unpunished. When we open ourselves to the word, when we talk about our personal history including our achievements and failures, there is always the temptation to present ourselves in a better light than reality justifies. Whether we give in to the temptation and how far we go in painting this favourable-and not entirely accurate-picture will depend on the level of our emotional integration and our ability to accept ourselves as we really are, but no one is, in principle, immune to the occasional misrepresentation which might earn one the others' respect, admiration or acceptance.

\footnotetext{
${ }^{27}$ Alvarez 2547.

${ }^{28}$ Alvarez 2547

29 Alvarez 2555.
} 
Moral imperfection is a feature of our shared humanity which justifies exercising forbearance towards pure autobiographical lies. Shiffrin explains: 'Where the motive of the wrongdoer reflects weakness, insecurity or fear, rather than animus, manipulativeness, or an objectionable insensitivity to particular people, demonstrating acceptance and inclusiveness may be especially apt. ${ }^{30}$

Those moral reasons justifying an accepting attitude towards the liar are motivated by toleration-related and not speech-related concerns. Shiffrin is scathing in her criticism of the reasoning in Alvarez, which held that the Stolen Valor Act was incompatible with freespeech principles. She concedes that the Act was a badly drafted piece of legislation which imposed disproportionate penalties, including imprisonment of up to a year, and gave rise to serious worries about selective prosecution and self-censorship. She thinks, though, that those are 'contingent objections to the particular version of legal regulation of lies embodied in the Stolen Valor Act and to its criminalization. ${ }^{31}$ A different, more moderate statute, using civil rather than criminal penalties should have passed constitutional muster because, in contrast to what the Supreme Court held, there are no independent, speech-related reasons which could have rendered it incompatible with the First Amendment.

Shiffrin identifies three such possible reasons, mentioned by the Supreme Court in Alvarez, and rejects all of them. First, she claims that the Act was not a clearly content-based restriction on speech because it aimed to regulate not the content of the speech (i.e. the lie as such) but 'the conjunction of the speaker's mental state toward the content, namely that the speaker believes it to be false, and her presentation of that content, nevertheless, as though it were true and believed by her to be true. ${ }^{32}$ Second, she denies that false statements might have free-speech value as a contribution to the quest for truth or an individual's project of discovering her true self. Lastly, she argues that there is no need to demonstrate the existence of a particularized harm caused by falsehoods in order to prohibit them and punish liars. It is to this third claim that I turn to in the following section.

\footnotetext{
${ }^{30}$ Shiffrin, Speech 177.

${ }^{31}$ Shiffrin, Speech 124.

32 Shiffrin, Speech 126.
} 


\section{THE VULNERABILITY OF TRUST}

Shiffrin is able to reject the need for some sort of particularized 'legally cognizable harm'33 before false speech is curtailed because she has already stated that lying as such damages the moral fabric of society in the form of undermining the force of testimonial warrants and spoiling the presumption of sincerity. This is the empirical argument which allows her to move from the normative claim that the mere utterance of falsehoods is, in principle, morally wrong to the conclusion that it should also constitute a legal wrong which the government can punish.

The first objection to Shiffrin's use of impersonal harm is that no evidence is offered for the truth of her empirical claim. There seems to be an assumption that the fabric of trust is so delicate that the mere expression of insincere speech, even where no one is deceived by it, is enough to tear it to pieces. Shiffrin could reply that she is not claiming that individual instances of lying will do so, but that the cumulative effect of repeated lying will have this effect by changing the nature of expression through speech. This takes us back to her explanation of the wrongness of lying: 'the wrong of lying is that it operates on a maxim that, if it were universalized and constituted a public rule of permissible action, would deprive us of reliable access to a crucial set of truths and a reliable way to sort the true from the false. ${ }^{34}$ The word 'universalized' is important here: if testimony were to be generally treated as a medium for conveying both truth and falsehood it would be impossible for speech to perform its function of distinguishing between the two. Therefore, the fabric of trust, which is constructed by the revelation of our genuine mental content to others, is particularly vulnerable to lying, which subverts the assumption that the revelation is sincere.

Shiffrin relies on her empirical claim that pure lying destroys the moral culture of sincerity to justify state coercion. While her worry is understandable, we should be more careful before granting the authorities the power to punish the mere utterance of insincerity. We should ask for some more convincing evidence than the invocation of some vague damage to an also rather vague moral fabric of trust. This is not to deny the moral function of testimony and the

\footnotetext{
${ }^{33}$ Shiffrin, Speech 157.

${ }^{34}$ Shiffrin, Speech 23.
} 
importance of truthful speech. But it is one thing to recognise its importance; it is quite another to use it as a justification for the government's sweeping power to punish, as the Supreme Court said in Alvarez, 'falsity and nothing more. ${ }^{35}$ A possible objection is that Shiffrin is making not an empirical but a deontological argument about the duty of sincerity in testimony. While this is true, it does not follow that evidence about the alleged harm is unnecessary. The claim underlying her account concerns the effect of lying, has an empirical dimension and calls for an evidentiary explanation of how lying spoils speech.

Besides, Shiffrin herself expects the production of specific empirical evidence in the context of deontological debates on free speech. She notes that opposition to the regulation of speech on the ground that it might lead to self-censorship-the 'chilling effect' argument-is often formulated in too casual a manner. ${ }^{36}$ She acknowledges that self-censorship is a serious and real issue but asks for a 'stronger evidentiary basis' of how governmental regulation stifles free expression. ${ }^{37}$ Those who rely on the chilling effect are, like Shiffrin, also making a normative argument about the conditions of communication, but she doesn't find this sufficient to absolve them of the obligation to supply evidence for their normative claims. And she is right not to take the proponents of the argument from selfcensorship on their word. But like Shiffrin, who looks for 'more precision and data about the chilling effect', ${ }^{38}$ we should also look for the same strong evidentiary basis, precision and data about the harm the mere expression of a lie inflicts on the culture of trust. If evidence is required of those who are concerned about the harm caused to speech, the same requirement should apply to those concerned about harm caused by speech.

Further, Shiffrin concedes that lying is an unavoidable feature of living with others in society: there are, she says, 'commonplace opportunities and temptations to lie in everyday life..$^{39}$ Perhaps this is too mild a description-it seems to me that in our relations with others, we lie, in the sense of not revealing our genuine mental

\footnotetext{
${ }^{35}$ Alvarez at 2545.

${ }^{36}$ Shiffrin, Speech $123 \mathrm{fn}$. 17. Shiffrin refers here to the analysis of chilling effect arguments in Leslie Kendrick, Speech, Intent and the Chilling Effect 54 William and Mary L. Rev. 1633 (2013).

${ }^{37}$ Shiffrin, Speech 123 fn. 17.

${ }^{38}$ Shiffrin, Speech 123 fn. 17.

${ }^{39}$ Shiffrin, Speech 177.
} 
content, and we are being lied to, all the time. In any case, it would be morally wrong and practically impossible to hold speakers liable whenever they are insincere, nor does Shiffrin so believe. Her account provides for situations where the moral obligation to reveal one's true mental content does not apply. She calls them 'suspended contexts': 'here, the normative presumption of truthfulness is suspended because these contexts serve other valuable purposes whose achievement depends upon the presumption's suspension and the fact and justification of the suspension are publicly available. ${ }^{, 40}$ When speaking within a suspended context 'the speaker's (potential) insincerity is reasonable and justifiable. ${ }^{41}$ She emphasises that this is a normative notion based on morally relevant reasons which are accessible to everyone. Put differently, a suspended context arises if and only if there is no normative expectation to be sincere. False statements made in a suspended context, she says, are not, properly speaking, lies. ${ }^{42}$ It follows that they are not morally wrong in the way lies are, and should be beyond the reach of the law.

We have already seen that Shiffrin thinks that false autobiographical statements are an example of falsehoods that should be tolerated. In the same category we find false statements which are necessary to protect another person's legitimate interests (the 'murderer at the door' example); ${ }^{43}$ those necessary for the speaker's privacy protection, self-protection and defence; ${ }^{44}$ responses to requests for information requiring a 'yes or no' answer without leaving room for clarifications; ${ }^{45}$ and statements made in the context of social etiquette. ${ }^{46}$ All these are falsehoods which are not, in a morally relevant sense, lies because they are expressed in circumstances which give rise to a suspended context where the obligation of sincerity does not obtain. Thus suspended contexts mitigate the harshness of the thesis that the law should punish pure lying and place a considerable amount of false speech beyond the reach of the government.

\footnotetext{
${ }^{40}$ Shiffrin, Speech 16.

${ }^{41}$ Shiffrin, Speech 16.

${ }^{42}$ Shiffrin, Speech 18. A different terminology would be to describe them as justified lies.

${ }^{43}$ Shiffrin, Speech 26 et seq.

${ }^{44}$ Shiffrin, Speech 149.

${ }^{45}$ Shiffrin, Speech 150-151.

${ }^{46}$ Shiffrin, Speech 153.
} 
While this approach makes very good sense, it is not easy to reconcile with Shiffrin's earlier claim that the fabric of trust can be destroyed by the mere utterance of falsehoods. Those suspended contexts, taken together, cover a very large part of our social lives and our relations with others. It would seem, therefore, that tolerating falsehood to such an extent would cause irreparable damage to the culture necessary to sustain sincere testimony. Shiffrin allows for too much lying: if sincerity is as vulnerable as she thinks it is, the combined effect of the suspended contexts would be to blur the distinction between lying and sincerity and create the impression that lies are a generally acceptable way of communicating with others.

I don't think it is convincing to reply that no harm to the culture of sincerity is caused because, in suspended contexts, there is no normative presumption of sincerity. Our emotional reaction and personal attitude to lying does not depend (or not entirely) on a Kantian calculation of the moral duties flowing from that presumption. My understanding of Shiffrin's position is that she is interested in the effect the utterance of falsehoods has not only on the norms associated with trust but also on the people involved in lying. Thus she accuses Justice Breyer of showing 'shocking insensitivity ${ }^{47}$ when he says in Alvarez that '...in family, social or other private contexts ... lies will often cause little harm'; ${ }^{48}$ falsehood, she retorts, can 'wreak special damage, ${ }^{, 49}$ on important personal and family relationships. This damage appears to be different from the harm caused on the impersonal communication warrants described earlier in the book; it is a more immediate, personal form of harm linked to the emotional experience of being lied to. In other words, personal attitudes towards sincerity and falsehood are also shaped by factors that transcend the normative element of human life; they will depend not only on the requirements of morality but also on a variety of emotions stirred up by the encounter with truth and lies. It appears, therefore, that whether lying causes harm cannot be answered by looking exclusively at whether the normative conditions for a suspended context obtain.

\footnotetext{
${ }^{47}$ Shiffrin Speech 136

48 Ibid.

49 Ibid.
} 
Perhaps the answer is that the fabric of trust is much more resilient than Shiffrin thinks. Despite the fact that we come in contact with falsehood, both as originators and recipients of it, on a daily basis, we don't despair of engaging in meaningful relations in our personal, social and professional lives, nor do we think that speech has lost its role as a means for expressing genuine mental content. Without closing our eyes to our and others' moral imperfections, so sensitively described by Shiffrin, we still find it possible to establish authentic connections. We learn to recognise indications of sincerity and build our own emotional and mental capacity to be sincere, and we develop our moral agency and a sense for morality's requirements. It is possible that when we find ourselves on the receiving end of insincerity, when our trust is betrayed and we realise that the other person has deliberately misled us, we feel that the possibility itself of sincere communication has been shattered to pieces. But if we are fortunate enough to have experienced sincerity in other relations, the pain and anxiety caused by particular instances of lying are mitigated and we are gradually able to regain our trust to speech as a medium for authenticity.

Moreover, unless we are entirely blind to our faults, we are able to recall our own lying and see ourselves not as the perpetual victims of false speech but also as the occasional perpetrators. A realisation that the same person can be, at different times, both a sincere speaker and a liar can also help us accept that testimony, as a medium, can convey both truth and falsehood, without the latter spoiling the former. By this I do not mean to downplay the difference between the two or suggest that they should merge into one. Rather, the condition I am describing is one of co-existence, not fusion. My suggestion is that when a view of speech as wholly 'pure' and exclusively dedicated to the expression of truth is replaced by the understanding that truth and falsehood are both parts of our collective communication framework, a more accurate and realistic picture of the function of speech develops and our trust in it is enhanced, not diminished.

I think that most people are able to mentally and morally contain, at the same time, two distinct realities: on the one hand, the many instances of lying in every aspect of human life; on the other, the need for authenticity in expressing one's mind and encountering the 
mind of others. This makes it possible to tolerate the frustration caused by lying and supports the conditions of truthful communication and the function of speech as a link between minds. If this sounds true, then Shiffrin's claim about the vulnerability of sincerity is less convincing.

\section{THE CAUSAL INQUIRY}

Even if Shiffrin's empirical claim is correct and there exists a moral fabric of trust delicate enough to be irreparably damaged by pure lying, the case for legally curtailing pure lies has not yet been made as not all harms caused by speech can legitimise the exercise of state coercion. It is necessary to ask if this impersonal harm is morally relevant in the sense that it can justify the censorship of false statements and the punishment of the speaker. As mentioned earlier, Shiffrin thinks it is. Recall that in her theory the evil that state coercion is meant to address is the destruction of the part of society's moral code which underpins the 'moral culture"50 or 'collective fabric $^{, 51}$ or "basis" ${ }^{52}$ of trust. She claims that this is enough because what is needed to legitimise the punishment of the liar is not particularised harm but some form of harm:

'The point of demanding a showing of harm is to ensure that speech is not regulated merely because many find it distasteful or to ensure that the regulation pursues a legally appropriate interest and does not regulate immoral behaviour as such. These are legitimate aims, but they do not entail a requirement of particularized harm. These constraints are satisfied if the motivation for regulation is to preserve the scheme of reliable communication or to adopt a public stance that reliability is a communal good. ${ }^{53}$

Thus the justificatory function we expect harm to perform is accomplished by the potential impersonal harm caused to society's morality.

This position entails two claims: first, that impersonal harm to abstract moral goods is a reason legitimatising state coercion; second, that there is no need for the government to show that there is a causal link between the measure it takes (i.e. punishing pure lies) and the damage it allegedly seeks to prevent (i.e. the destruction of the moral fabric of sincerity). While there are objections to the first

\footnotetext{
${ }^{50}$ Shiffrin, Speech 163.

${ }^{51}$ Shiffrin, Speech 157.

52 Shiffrin, Speech 131.

${ }^{53}$ Shiffrin, Speech 138 (emphasis in the original).
} 
claim, I will focus on the second claim because it is particularly relevant for constitutional doctrine on free speech.

The issue of causation came up in Alvarez. The U.S. government conceded that 'an isolated misrepresentation by itself would not tarnish the meaning of military honors' but asserted that it is common sense that false representations have the tendency to dilute the value and meaning of military awards. ${ }^{54}$ Put in Shiffrin's terms, the government was saying that the function of military awards was to establish a system of testimonial warrants: an award or medal communicates to the world that the recipient served with great distinction and bravery, and this communication works only if we can be certain that its content is true. We respect the recipient because we trust that the message conveyed by the award is accurate. Repeated false claims by impostors, if left unpunished, will diminish the reliability of the awards system and, therefore, its function as a medium for recognising truly distinguished service will be compromised. If it becomes generally accepted that a military award might not constitute reliable testimony, the fabric of trust underpinning the awards system is damaged and, therefore, the meaning of awards is spoiled.

The Supreme Court was rightly not persuaded. Justice Kennedy noted that the Constitution requires the government to show that there is a link between lying about the award and the potential harm to the military awards system before it is allowed to limit the liberty to speak, and found that beyond its assertion that the meaning of the awards will be diluted, it had failed to provide any evidence that such a causal link existed. Shiffrin's criticism is that he shouldn't have asked for it at all, as the damage to the 'collective testimonial framework ${ }^{55}$ underpinning military awards and the possibility that we might come to doubt the validity of the message conveyed by the awards are enough to justify state coercion.

Shiffrin does not pay enough attention to the importance of the causal inquiry in constitutional adjudication in general, and free speech cases in particular. In American constitutional law, the dangers of doing away with a causation test are exemplified in the three

\footnotetext{
${ }^{54}$ Alvarez at 2549 (internal quotation marks omitted).

${ }^{55}$ Shiffrin, Speech 136.
} 
infamous First World War speech cases: Schenck, ${ }^{56}$ Frohwerk ${ }^{57}$ and Debs. ${ }^{58}$ All three concerned convictions under the Espionage Act 1917 which had criminalised conduct likely to interfere with the war effort by causing insubordination in the armed forces or interfering with recruitment. Schenck was about the distribution of anti-war leaflets criticising the draft and encouraging people to oppose it, while Frohwerk involved a series of newspaper articles which argued that the war served capitalist interests and that those who refused to fight could not be blamed. The Supreme Court, in opinions written by Justice Holmes, upheld the convictions. In Schenck he stated that the test was whether there was a 'clear and present danger' that the speech in question could cause the harm the government was trying to prevent and that this was a matter of 'proximity and degree'. Although there was no evidence whatsoever that the leaflets had had any effect on the war effort he held that proximity was satisfied because they had the 'tendency" to do so.

Justice Holmes applied the same test to the articles at stake in Frohwerk and, again, held that the lack of any nexus between them and the alleged harm was not an issue because they could cause future harms by affecting the attitude of people towards the war: ' $[I] \mathrm{t}$ is impossible to say that it might not have been found that the circulation of the paper was in quarters where a little breath would be enough to kindle a flame and that the fact was known and relied upon by those who sent the paper out. ${ }^{60}$ Debs was even more problematic as it involved speech at a political forum par excellence. The defendant, the presidential candidate of the Socialist Party, had spoken at the party conference criticising world capitalism and the war and praising his comrades who had been convicted of aiding and abetting others in not registering for the draft. For the third time, Justice Holmes held that Debs's speech did not enjoy First Amendment protection because it had the 'natural tendency ${ }^{61}$ negatively to affect societal attitudes to the draft and the war.

\footnotetext{
${ }^{56}$ Schenck v. United States, 249 U.S. 47 (1919).

${ }^{57}$ Frohwerk v. United States, 249 U.S. 204 (1919).

${ }^{58}$ Debs v. United States, 39 S. Ct. 252 (1919).

59 Schenck v. United States, 249 U.S. 47, 52 (1919).

${ }^{60}$ Frohwerk v. United States, 249 U.S. 204, 209 (1919).

${ }^{61}$ Debs v. United States, 39 S. Ct. 252, 254 (1919).
} 
In all three cases the causation test applied is extremely lax: a possible tendency of speech to affect the way citizens viewed the war was enough to satisfy it. It was this lack of a serious causal inquiry which deprived the clear and present danger test of any bite and turned it into a mechanism of wholesale deference to the government. The fact that the speech in question was clearly political in nature, did not constitute incitement to violence and concerned a matter of the utmost public interest was not enough to protect those whose views were inconvenient for the government. Accepting that the possibility of harm to a societal value (like bravery at war or commitment to sincerity) can legitimise censorship without any showing of a link between speech and harm amounts to granting the state practically unlimited power to curtail speech. The Supreme Court acknowledged this danger in Brandenburg v. Ohio which overruled Justice Holmes's test and held that the government must tolerate even the advocacy of law violation 'except where such advocacy is directed to inciting or producing imminent lawless action and is likely to incite or produce such action. [The] mere abstract teaching of the moral propriety or even moral necessity for a resort to force and violence, is not the same as preparing a group for violent action and steeling it to such action' ${ }^{62}$

More recently, a strategy similar to that of Justice Holmes in relation to causation has been used by the European Court of Human Rights in cases concerning speech which offends public morality. Muller and others $v$. Switzerland ${ }^{63}$ was about the confiscation by the Swiss authorities of the applicant's paintings depicting sexual scenes and his conviction for publishing obscene material. The paintings were on show at an art space where the public was given access free of charge. The court upheld the confiscation and conviction against a challenge based on the right to freedom of expression under article 10 of the European Convention on Human Rights. ${ }^{64}$ The government argued that the paintings were harmful

${ }^{62}$ Brandenburg v. Ohio, 395 U.S. 444, 448 (1969).

${ }^{63}$ (1991) 13 EHRR 212.

${ }^{64}$ Article 10: 1. 'Everyone has the right to freedom of expression. This right shall include freedom to hold opinions and to receive and impart information and ideas without interference by public authority and regardless of frontiers. This Article shall not prevent States from requiring the licensing of broadcasting, television or cinema enterprises. 2. The exercise of these freedoms, since it carries with it duties and responsibilities, may be subject to such formalities, conditions, restrictions or penalties as are prescribed by law and are necessary in a democratic society, in the interests of national security, territorial integrity or public safety, for the prevention of disorder or crime, for the protection of health or morals, for the protection of the reputation or rights of others, for preventing the disclosure of information received in confidence, or for maintaining the authority and impartiality of the judiciary.' 
for public morality ${ }^{65}$ and the domestic courts agreed stating: 'any item is obscene which offends, in a manner that is difficult to accept, the sense of sexual propriety' ${ }^{66}$ and 'these are not works which, in treating a particular subject or scene, allude to sexual activity more or less discreetly. They place it in the foreground, depicting it not in the embrace of man and woman but in vulgar images of sodomy, fellatio between males, bestiality, erect penises and masturbation. Sexual activity is the main, not to say sole, ingredient of all three paintings .... ${ }^{, 67}$

The European court held not only that the moralistic preferences of the majority were a morally sufficient reason for censorship but also allowed the confiscation and conviction to pass muster without evidence of a causal link between speech and the alleged harm to the fabric of sexual morality. The applicant argued that his paintings did not cause public morals to deteriorate as there was no public outcry, the press had supported his right to exhibit his art and he had been able to do so both before and after the exhibition at stake in the case. Yet, the court did not discuss the argument, pointing instead to the judgments of the domestic courts which had found that the provocative nature of the paintings was liable to offend the sense of sexual propriety ${ }^{68}$ and that this was enough to justify governmental action.

A possible reply is that those are instances of content-based restrictions of speech. The government was censoring a communication because it disagreed with the message it conveyed, whereas the regulation of lies, Shiffrin has argued, is content-neutral. However, even if this is true, it does not follow that the causal inquiry can be ignored. Shiffrin takes the view that the regulation of lies is analogous to the so called 'time, place and manner' restrictions on speech, ${ }^{69}$ typical examples of which are regulations for noise control, traffic control and the use of public property. But, while it is true that the Supreme Court applies to those restrictions a more deferential

\footnotetext{
${ }^{65}$ The government also invoked the 'rights of others' as a reason justifying the confiscation because a father had taken his daughter to the gallery and she had 'reacted violently' upon seeing the painting. The court was clear that the government's aim was the protection of morality: 'The applicants' conviction ... was intended to protect morals.' (paragraph 35).

${ }^{66}$ Muller, paragraph 18.

${ }^{67}$ Muller, paragraph 16 .

${ }^{68}$ Muller, paragraph 18.

${ }^{69}$ Shiffrin, Speech 126.
} 
standard of review than the usual strict scrutiny test applied to content-based measures, it also requires the government to demonstrate that the harms it seeks to avoid by curtailing speech are real and that the limitations are narrowly drawn to serve an important state interest. ${ }^{70}$ Put differently, the fact that a restriction hinges on the time, place and manner of the communication, as opposed to its content, is not enough to save it if the government cannot provide evidence that there is an empirically justifiable match between its action and the aim it pursues. Even if the Stolen Valor Act were a content-neutral statute, similar to a time, place and manner regulation, the Supreme Court would still be justified in asking the government to show that there was a link between lying about a military award and the alleged damage to the military awards system. $^{71}$

I am not saying that Shiffrin would agree with the outcome of the cases discussed earlier, or that her theory inevitably leads to such results or that she would endorse majoritatian moralism. Rather, my concern is that she underestimates the importance of the causal inquiry in constitutional adjudication. Expecting the state to satisfy a rigorous causation test is an important safeguard for civil liberties, and the history of free speech jurisprudence shows that it performs an essential role as a limit to governmental zeal to regulate what can and cannot be said. From the point of view of constitutional adjudication in freedom of expression cases, her approach is very close to the 'clear and present danger' test and difficult to reconcile with the Brandenburg standard, which rejects abstract threats to societal interests as a legitimate basis for censorship. If Shiffrin's account, philosophically compelling and elegant as it is, were to become a

\footnotetext{
${ }^{70}$ See e.g. US v. Grace, 461 U.S. 171 (1983); Clark v. Community for Creative Non-Violence, 468 U.S. 288 (1984); Ward v. Rock Against Racism, 491 U.S. 781 (1989).

${ }^{71}$ The Supreme Court explored further the issue of punishment for false statements in Maslenjak $v$ United States 137 S.Ct. 1918 (2017). The claimant, a refugee from former Yugoslavia, had been given asylum in the United States and was subsequently naturalised as a U.S. citizen. When it emerged that she had lied about the participation of her husband in the civil war, she lost her citizenship and was deported under a federal provision which made it a crime to procure naturalisation 'contrary to law'. The government's argument was that since she had lied during the naturalisation proceedings she had broken another law which criminalises the making of a false statement under oath in such proceedings. In an opinion by Justice Kagan, the Court held that making a false statement as such was not enough for a conviction; the government also needs to demonstrate that the lies had a material effect in the acquisition of citizenship. While the case was not decided on free speech grounds, it is relevant for the issue of causation discussed here. Following a similar approach as in Alvarez, the Court required evidence of a causal link between lying and obtaining citizenship, refusing to uphold punishment for falsity which does not actually deceive.
} 
standard of adjudication, the protection for speech would significantly deteriorate.

\section{OPEN ACCESS}

This article is distributed under the terms of the Creative Commons Attribution 4.0 International License (http:// creativecommons.org/licenses/ by/4.0/), which permits unrestricted use, distribution, and reproduction in any medium, provided you give appropriate credit to the original author(s) and the source, provide a link to the Creative Commons license, and indicate if changes were made.

City, University of London, London, UK

E-mail:nicholas.hatzis.1@city.ac.uk 